\title{
ВХІДНІ ФІЛЬТРИ УНІВЕРСАЛЬНИХ КОЛІЙНИХ ПРИЙМАЧІВ ТОНАЛЬНИХ РЕЙКОВИХ КІЛ
}

Р.М. Писар, канд. техн. наук В.Ш. Хісматулін

ВХОДНЫЕ ФИЛЬТРЫ УНИВЕРСАЛЬНЫХ ПУТЕВЫХ ПРИЕМНИКОВ ТОНАЛЬНОЙ РЕЛЬСОВЫХ ЦЕПЕЙ

Р.М. Писарь, канд. техн. наук В.Ш. Хисматулин

\section{INPUT FILTERS UNIVERSAL RECEIVER TONAL TRACK RAIL CIRCUITS}

R.M Pysar, cand. of techn. sciences V.S Hismatulin

Розглянуто доиільні схеми вхідних фільтрів колійних приймачів тональних рейкових кіл, побудованих за прямим перетворенням та засупергетеродинним принципом. Встановлено, щзо при виборі проміжної частоти в межах 1200 - 1400 Гц вони можуть бути реалізовані як смугові фільтри, щуо розраховуються на базі фільтрів низьких та високих частот Чебишева або Баттерворта третього порядку.

Ключові слова: тональні рейкові кола, колійний приймач, пряме перетворення, супергетеродин, фільтр Чебишева, фільтр Баттерворта. 
Рассмотрены целесообразные схемы входных фильтров путевых приемников тональных рельсовых иеепей, построенных по схеме прямого преобразования и по супергетеродинному принципу. Установлено, что при выборе промежуточной частоты в пределах 1200 - 1400 Ги они могут быть реализованы как полосовые фильтры, которые рассчитываются на базе фильтров низких и высоких частот Чебышева или Баттерворта третьего порядка.

Ключевые слова: тональные рельсовые цепи, путевой приемник, прямое преобразование, супергетеродин, фильтр Чебышева, фильтр Баттерворта.

The expedient charts of entrance filters of the ground receivers of voice-frequency rail chains, built on superheterodyne principle are considered. It is set that at the choice of intermediate frequency within the limits of $1200-1400 \mathrm{~Hz}$ they can be realized as bandpass filters which settle accounts on the base of filters of low and high frequencies of Chebyshev or Batterworth of the third order.

Keywords: tone track circuits, track receiver, direct conversion superheterodyne, Chebyshev filter, Butterworth filter.

Зараз у складі апаратури ТРК3 та ТРК4 блок колійного приймача має двадцять різновидів (виконань), яки відрізняються несучою частотою i частотою модуляції робочого сигналу [1]. Велика кількість різновидів колійних приймачів обумовлена наявністю у їх складі вузькосмугових вхідних фільтрів. Відповідно до принципу побудови колійних приймачів як приймачів прямого підсилення, вхідні фільтри настроюються на одну 3 частот ТРК і у подальшому не можуть бути перестроєними. Саме тому й виникає необхідність у великій кількості різновидів колійних приймачів.

За вказаними причинами доцільно розглянути варіант побудови колійного приймача супергетеродинного типу або прямого перетворення [2]. У супергетеродинному приймачі настроювання на частоту $f_{c}$ сигналу ТРК здійснюється встановленням частоти гетеродина $f_{2}$, а проміжна частота $f_{n}=\left|f_{c}-f_{2}\right|$, на якій здійснюється фільтрація сигналів на частотах $f_{c \kappa}$ сусідніх каналів, не змінюється. Тому він може перенастроюватись на будь-яку частоту ТРК зміною частоти гетеродина $f_{2}$ без перестроювання вхідного фільтра.
Недоліком супергетеродинного принципу побудови $є$ наявність дзеркального каналу приймання [2]. Частота дзеркального каналу приймання $f_{\partial \kappa}$, на якій сигнал може проходити на вихід приймача, знаходиться на відстані від частоти $f_{c}$ основного каналу, яка дорівнює подвійному значенню проміжної частоти:

$$
\left|f_{c}-f_{\partial \kappa}\right|=2 f_{n}
$$

Заглушення дзеркального каналу приймання здійснюється у вхідному фільтрі. Вимоги до вхідного фільтра залежать від рівня завад на частотах $f_{\partial \kappa}$. Якщо на частотах дзеркальних каналів відсутні сигнали тональних рейкових кіл та будь-які інші сигнали, то вимоги до вибірковості вхідних фільтрів будуть мінімальними. 3 цієї точки зору найбільш доцільне значення проміжної частоти знаходиться в межах від 1200 до 1500 Гц. Таке значення проміжної частоти також дозволяє побудувати достатньо прості фільтри зосередженої селекції на проміжній частоті.

На відміну від супергетеродинного приймача приймач прямого перетворення не має дзеркальних каналів приймання. 
Тому відсутня необхідність у заглушенні бічних каналів. Однак $з$ метою зменшення негативного впливу гармонік тягового струму також доцільно ввести смуговий фільтр, за допомогою якого виконується вказана функція.

Отже, відповідно до виразу (1), смуга перепускання вхідного фільтра може мати порядок 1000 Гц, а його схема може бути достатньо простою. Тому вхідний фільтр може бути виконаний як смуговий фільтр, що охоплює досить великий діапазон частот (рис. 1). Для колійних приймачів доцільно застосувати два окремі смугові фільтри: один для частот 420-780 Гц, а інший для частот 4555-5555 Гц.

Для побудови смугового фільтра на LC-елементах застосовують схеми, амплітудно-частотні характеристики (АЧХ) яких апроксимують поліномами Чебишева, степеневими функціями Баттерворта та еліптичними функціями Кауера. Тип та необхідний порядок фільтру визначається заданим згасанням при припустимому значенні коефіцієнта нерівномірності АЧХ $A_{p}$.

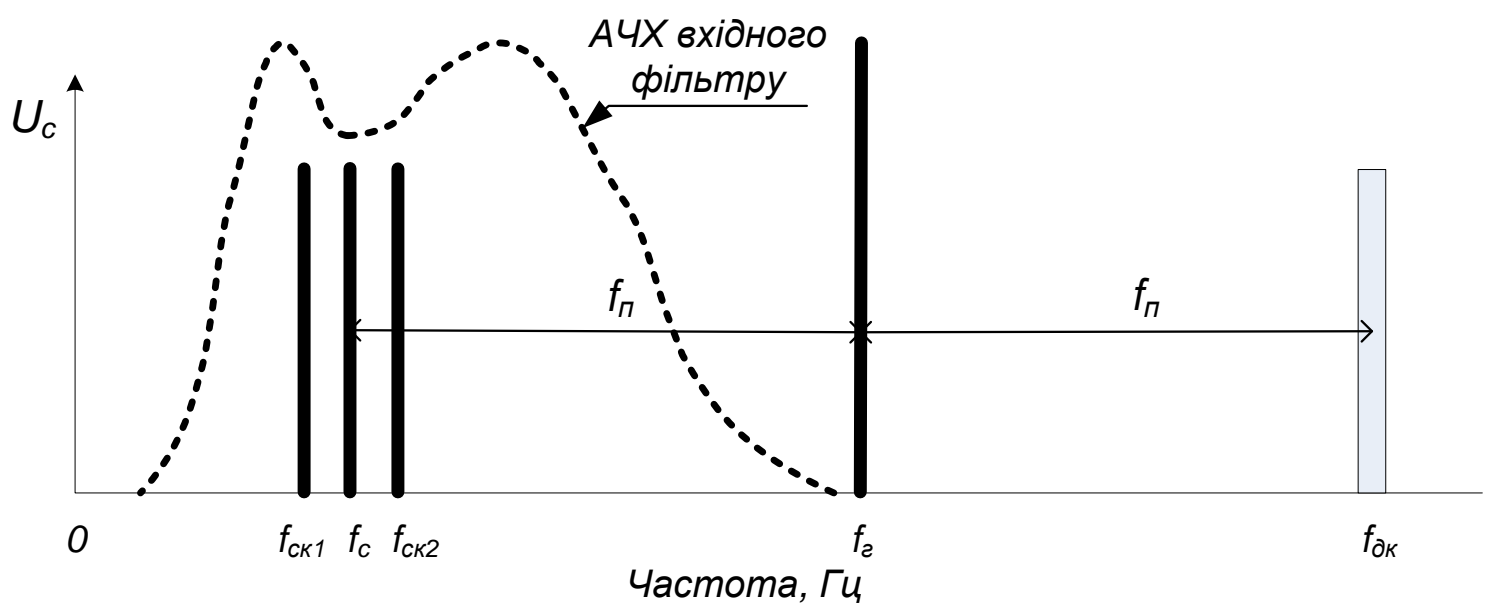

Рис. 1

Найпростішими у реалізації є фільтри Чебишева та Баттерворта третього порядку. У фільтрів третього порядку спад АЧХ поза межами області прозорості дорівнює 18 дБ/октаву [3]. Якщо таке згасання $\epsilon$ недостатнім, то додають додаткові ланки 3 двох елементів $L C$. Кількість ланок визначає порядок фільтру.

Типові схеми фільтрів верхніх та низьких частот Чебишева та Баттерворта третього порядку наведені на рис. 2. Тут $R 1, R 2$ - вхідний та вихідний опори фільтра. У випадках, коли смуга перепускання фільтра дорівнює або більше однієї октави, результуючий смуговий фільтр будують як послідовне з'єднання відповідних ФНЧ та ФВЧ [3].

За методикою, що наведено у [3], проведено розрахунки фільтрів Чебишева та Баттерворта для вхідного та вихідного опорів $R 1=R 2=150$ Ом, частот зрізу фільтра ВЧ $f_{c ̧ 1}=400$ Гц, фільтра НЧ $f_{c ̧ 2}=800$ Гц. Вказані дані відповідають характеристикам колійних приймачів частотного діапазону 420-780 Гц [1].

За результатами розрахунків проведено моделювання фільтрів із застосуванням програмного середовища MULTISIM [4]. 


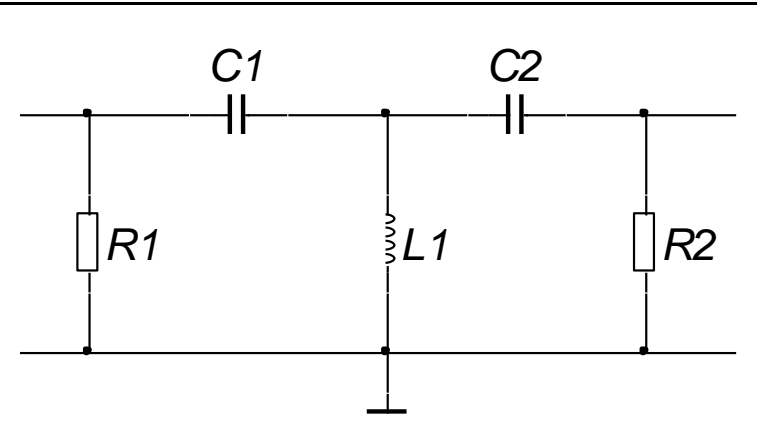

a

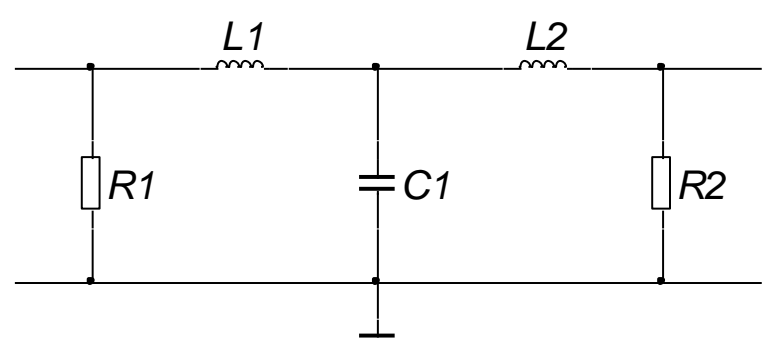

B
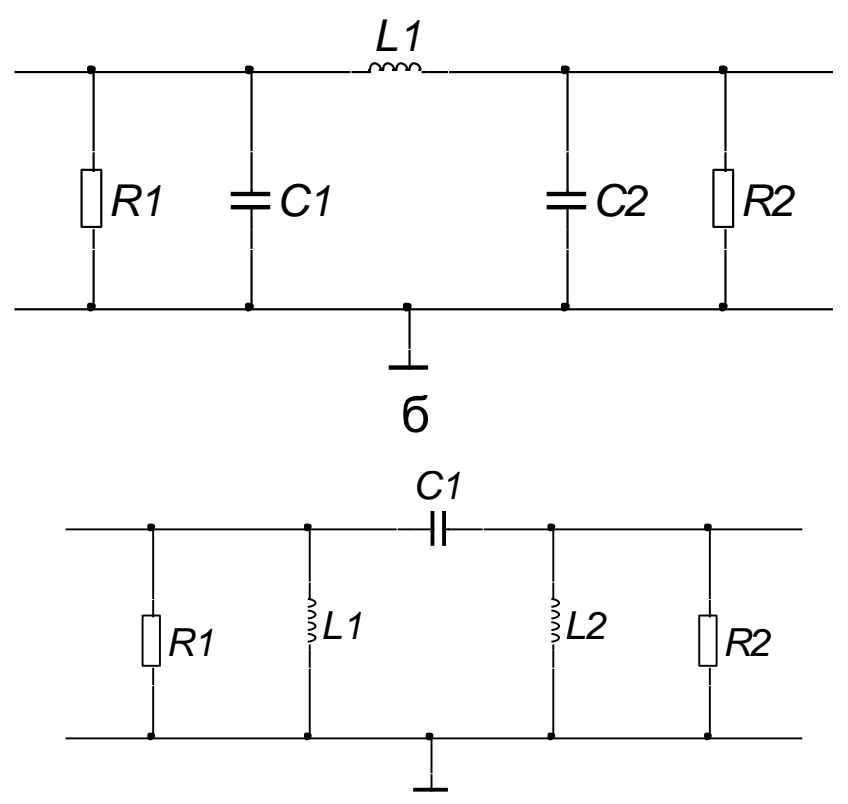

$\Gamma$

а - Т-фільтр верхніх частот; б - П-фільтр низьких частот;

в - Т-фільтр низьких частот; г - П-фільтр верхніх частот

Рис. 2

За результатами моделювання можна зробити такі висновки.

1. Амплітудно-частотна характеристика фільтра Чебишева $є$ більш рівномірною.

2. Фільтр НЧ Баттерворта забезпечує більше згасання поза межами смуги пропускання. Так, на частоті 3580 Гц фільтр НЧ Баттерворта дає згасання - 26 дБ, а фільтр Чебишева - 23,7 дБ.

3. Фільтр ВЧ Чебишева забезпечує більше згасання поза межами смуги пропускання. Згасання - 20 дБ він забезпечує на частоті 149,2 Гц, а фільтр Баттерворта - на частоті 127,5 Гц.

Результуючий смуговий фільтр доцільно побудувати як послідовне з'єднання ФНЧ Баттерворта та ФВЧ Чебишева. Принципову схему вхідного фільтра для частот ТРК3 наведено на рис. 3. На рис. 4 наведено результати моделювання вхідного фільтра у програмному середовищі MULTISIM.

Проведемо аналіз отриманих результатів.

1. Вхідний фільтр має смугу пропускання від 250 до 1000 Гц, причому у межах частот 420 - 780 Гц нерівномірність АЧХ дорівнює 0,266 дБ.

2. При проміжній частоті 1400 Гц заглушення частот дзеркальних каналів приймання 3220-3580 Гц перевищує 25 дБ.

3. Заглушення сигналів з частотою до 50 Гц перевищує 50 дБ, з частотою до 75 Гц - 40 дБ, з частотою до 150 Гц - 20дБ.

Таким чином, у колійному приймачі прямого перетворення та у приймачі супергетеродинного типу вхідний смуговий фільтр можна побудувати як послідовне з'єднання ФНЧ Баттерворта та ФВЧ Чебишева 3 порядку. 
Автоматика та комп'ютерні системи управління рухом поӥздів

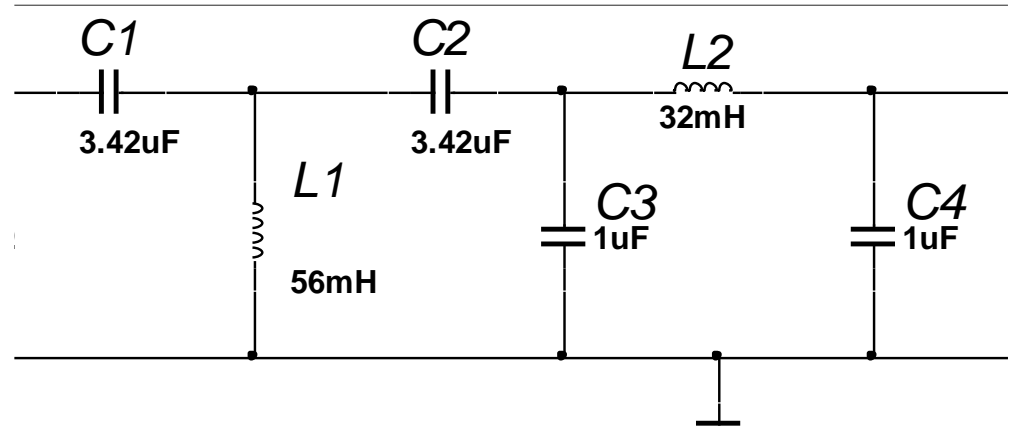

Рис. 3. Схема моделі вхідного фільтру в програмі Multisim

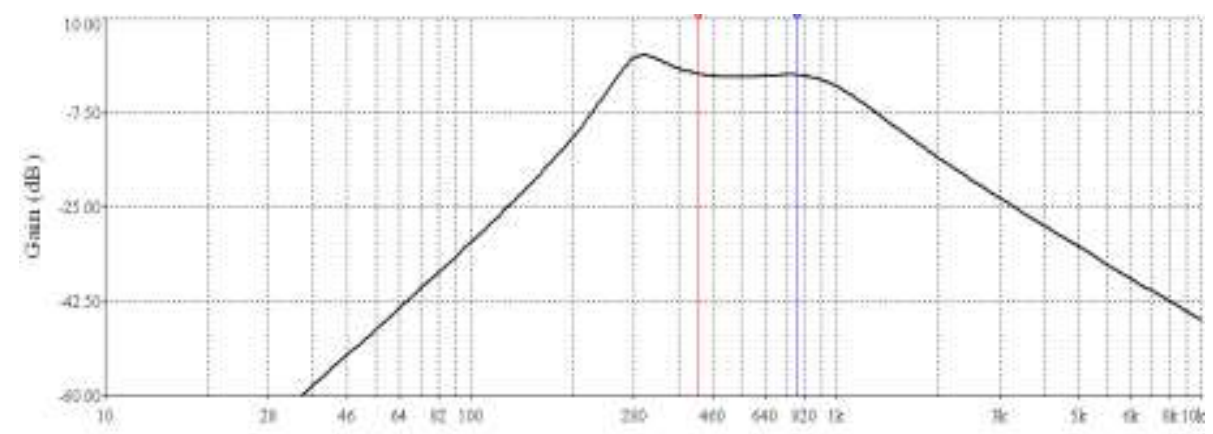

Рис. 4. Результати моделювання АЧХ вхідного фільтра

\section{Список використаних джерел}

1. Кулик, П.Д. Практичний посібник з технічного утримання апаратури тональних рейкових кіл [Текст] / П.Д. Кулик, О.О. Удовіков, В.І. Басов [та ін.]. - К.: Укрзалізниця, 2006. $-236 \mathrm{c}$.

2. Головин, О.В. Радиоприемные устройства [Текст] / О.В. Головин. - М.: Горячая линия-Телеком, 2002. - 368 с.

3. Ред, Э. Справочное пособие по высокочастотной схемотехнике [Текст] / Э. Ред. - М.: Мир, 1990. - 256 с.

4. Карлащук, С.В. Электронная лаборатория Electronics Workbench [Текст] / С.В. Карлащук. - СПб.: ПИТЕР, 2002. - 642 с.

Писар Романа Миколаївна, слухач групи МЗ-АТЗ-АКСУРП-Б-11.

Хісматулін Володимир Шайдуллович, канд. техн. наук, професор, кафедра автоматики та комп'ютерного телекерування рухом поїздів.

Pysar R.M., cand. of techn. sciences, prof. V.S. Hismatulin 